\title{
Lung Parenchyma Tumor Location
}

National Cancer Institute

\section{Source}

National Cancer Institute. Lung Parenchyma Tumor Location. NCI Thesaurus. Code C159210.

A section header to choose the location of the parenchyma in the lung. 